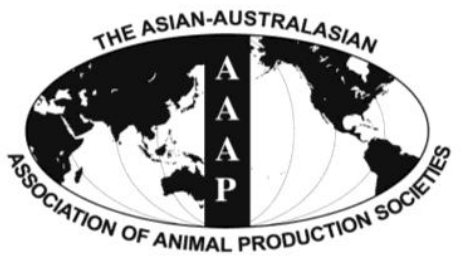

Asian-Aust. J. Anim. Sci.

Vol. 25, No. 5 : 682 - 689

May 2012

www.ajas.info

http://dx.doi.org/10.5713/ajas.2011.11334

\title{
Growth Performance and Meat Quality of Broiler Chickens Supplemented with Bacillus licheniformis in Drinking Water
}

\author{
Xiaolu Liu, Hai Yan*, Le Lv, Qianqian Xu, Chunhua Yin, Keyi Zhang, Pei Wang and Jiye Hu \\ Department of Biological Science and Engineering, School of Chemical and Biological Engineering, \\ University of Science and Technology Beijing, Beijing 100083, China
}

\begin{abstract}
A feeding trial was conducted to investigate effects of Bacillus licheniformis on growth performance and meat quality of broilers. Nine hundred one-d-old broiler chicks were randomly assigned to 3 experimental groups with three replicate pens of 100 broiler chicks. Three treatments were i) control, ii) basal diets supplemented with $1 \mathrm{ml}$ of $B$. licheniformis for each in feed water per day iii) basal diets supplemented with $2 \mathrm{ml}$ of $B$. licheniformis per chick in feed water per day. The supplementation of $B$. licheniformis significantly increased body weight in grower chickens $(\mathrm{p}<0.05)$, and significantly improved the feed conversion in 3 to 6 and 0 to 6 wk feeding period compared with the control group $(\mathrm{p}<0.05)$. Additionally, the supplement also resulted in increased protein and free amino acid contents, and decreased fat content in chicken breast fillet $(\mathrm{p}<0.05)$. Furthermore, improvement in sensory attributes was observed in broilers fed with the probiotic. In conclusion, B. licheniformis treatments resulted in a significant increase $(\mathrm{p}<0.05)$ in broiler productivity based on an index taking into account daily weight gain and feed conversion rate. Meanwhile, the probiotic contributed towards an improvement of the chemical, nutritional and sensorial characteristics of breast fillet. Overall, the study indicates that B. licheniformis can be used as a growth promoter and meat quality enhancer in broiler poultry. (Key Words: Poultry, Bacillus licheniformis, Probiotic, Growth Performance, Meat Quality)
\end{abstract}

\section{INTRODUCTION}

According to the definition by FAO/WHO, probiotics are: "Live microorganisms which when administered in adequate amounts confer a health benefit on the host" (Fuller et al., 1989). Currently, probiotics seem to be a good alternative to the use of antibiotics as growth promoters (Tomasik and Tomasik, 2003), which have been used on poultry and livestock in an attempt to increase mean weight gain (Tannock et al., 1999). In broiler nutrition, probiotic species such as Lactobacillus, Streptococcus, Bacillus, Bifidobacterium, Enterococcus, Aspergillus, Candida, and Saccharomyces are widely used to prevent poultry pathogens and diseases and improve broiler's growth performance (Tortuero, 1973; Owings et al., 1990; Jin et al., 1998; Zulkifli et al., 2000; Kalavathy et al., 2003; Kabir et al., 2004; Gil De Los Santos et al., 2005; Timmerman et al, 2006; Mountzouris et al., 2007; Awad et al., 2009 ).

As a widely used probiotic strain, Bacillus licheniformis

\footnotetext{
* Corresponding Author: Hai Yan. Tel: +86-25-62333177, E-mail: haiyan@sas.ustb.edu.cn

Submitted Sept. 16, 2011; Accepted Dec. 28, 2011; Revised Jan. 24, 2012
}

is considered one of the most health- boosting bacteria because it has demonstrated a positive effect in aiding nutrient digestion and absorption in the host's body (Scgarrd and Demark, 1990). B. licheniformis has been broadly applied in livestock animals as a growth promoter and a competitive exclusion agent. Besides, it has been used recently in aquaculture to enhance the growth and diseaseresistance of cultured shrimps (Simon M. 2010). At present, $B$. subtilis and B. licheniformis are often used together in two products, Biosporin and BioPlus 2B. BioPlus 2B is used in animal feed while Biosporin is licensed as a medicine (SCAN, 2000b; Osipova et al., 2005). BioPlus 2B has been studied by many researchers regarding its efficacy in the suppression of gastrointestinal pathogens. Results of these studies guaranteed its registration as a feed supplement. It showed that the ingestion of BioPlus 2B increases growth performance, feed conversion, and meat quality during the weaning, growing and finishing stages of piglet growth (Kyriakis et al., 1999; Alexopoulos et al., 2004). It remains unclear whether there is any added benefit in the combined use of the two strains. Although there have been a few investigations on effects of $B$. licheniformis in poultry, little information is available on its impact on 
nutrient metabolism and histological alterations to intestine in chickens. In particular, the use of B. licheniformis spores as a probiotic or a direct-fed microorganism could be an alternative to adding medicine to feed in the prevention and treatment of broiler chickens' necrotic enteritis under commercial-like conditions (Knap et al., 2010). Therefore, when used as a poultry growth promoter, B. licheniformis spores added to feed could enhance broiler chicken's growth.

To further prove the potential of B. licheniformis in improving growth performance and meat quality of broilers, we investigated the effect of $B$. licheniformis supplemented in drinking water. Meanwhile, broiler's growth performance parameters including body weight (BW), weight gain (BWG), feed intake (FI), feed conversion ratio (FCR) and mortality of chicken (MC) were monitored. Consumers' acceptance test of chicken breast fillet from treated chickens was conducted to evaluate the applicability of $B$. Licheniform in commercial broilers and confirm improvement of meat qualitative traits.

\section{MATERIALS AND METHODS}

\section{Probiotic strains}

A bacteria strain of B. Licheniform (NO. 1.265) was bought from China General Microbiological Culture Collection Center and cultured at $35^{\circ} \mathrm{C}$ with a shake rate of $200 \mathrm{rpm}$ for $1 \mathrm{~d}$. The cells were harvested with the centrifugation at $12,000 \mathrm{rpm}$ for $20 \mathrm{~min}$, and the cell solution containing $5.6 \times 10^{9}$ colony-forming units per $\mathrm{ml}$ in water was used to feed broiler chicks by mixing with drinking water.

\section{Birds and dietary treatments}

All practices carried out on animals in the course of this study followed principles required by the University. Nine hundred one-d-old broiler chicks were randomly assigned to 3 experimental groups with three replicate pens of 100 chicks (50 male and 50 female) each, and raised on floor pens $\left(0.90 \mathrm{~m}^{2} / \mathrm{bird}\right)$ for $6 \mathrm{wk}$. Chicks were vaccinated at hatch for Marek, Infectious Bronchitis and Newcastle Disease. Feed and water were supplied for consumption ad libitum. Chicks were fed a commercial maize-soybean diet without any antibiotics or growth promoters, which was formulated for starter (0 to $3 \mathrm{wk}$ ), grower (3 to $6 \mathrm{wk}$ ) growth periods (Table 1). The temperature was set at $32^{\circ} \mathrm{C}$ on the first day, gradually reduced to $24^{\circ} \mathrm{C}$ by the third week, and then maintained at $24^{\circ} \mathrm{C}$ to the end of the experiment. The drinking water was untreated well water with the following properties: $\mathrm{pH} 7.5$, electrical conductivity $570 \mathrm{mmohs} / \mathrm{cm}$ and free residual chlorine 0 $\mathrm{mg} / \mathrm{L}$. B. licheniformis was provided through drinking water and prepared daily. Chicks of group 1 (Control) were
Table 1. Composition of the basal diet

\begin{tabular}{lcc}
\hline \multirow{2}{*}{ Ingredients } & Starter & Grower \\
\cline { 2 - 3 } & (d 0 to 21) & (d 22 to 42) \\
\hline Composition (g/kg) & 535.3 & 588.6 \\
Maize & 355.2 & 315.3 \\
Soybean meal & 39.9 & 36.3 \\
Fish meal & 35.2 & 30.2 \\
Vegetable oil & 15.2 & 12.7 \\
limestone & 3.0 & 3.0 \\
Salt & 9.2 & 7.8 \\
Monocalcium phosphate & 2.0 & 2.0 \\
Vitamin premix ${ }^{\mathrm{a}}$ & 2.0 & 2.0 \\
Mineral premix & $\mathrm{b}$ & 1.0 \\
DL-methionine & 1.5 & 0.6 \\
L-lysine & 1.0 & 0.5 \\
Choline chloride & 0.5 & 12.8 \\
Calculated chemical composition (g/kg wet weight) & \\
ME (MJ/kg) & 12.9 & 88.7 \\
Dry matter & 88.9 & 206.3 \\
Crude protein & 221.6 & 9.5 \\
Lysine & 11.2 & 7.6 \\
Methionine+cystine & 8.5 & 8.7 \\
Calcium & 10.2 & 6.3 \\
Total phosphorus & 6.9 & \\
\hline
\end{tabular}

${ }^{a}$ The vitamin premix supplied the following per kilogram of diet: vitamin A, 9,800 IU; vitamin $\mathrm{D}_{3}, 2,200 \mathrm{IU}$; vitamin E, $40 \mathrm{IU}$; vitamin $\mathrm{K}_{3}, 2 \mathrm{mg}$; thiamine, $1 \mathrm{mg}$; riboflavin, $7 \mathrm{mg}$; pyridoxine, $6 \mathrm{mg}$; vitamin $\mathrm{B}_{12}, 0.035$ $\mathrm{mg}$; nicotinic acid, $50 \mathrm{mg}$; pantothenic acid, $15 \mathrm{mg}$; folic acid, $1.5 \mathrm{mg}$; biotin, $0.15 \mathrm{mg}$.

${ }^{\mathrm{b}}$ The mineral premix supplied the following per kilogram of diet: Fe, 70 $\mathrm{mg}$; Cu, $9 \mathrm{mg}$; Mn, $90 \mathrm{mg}$; Zn, $60 \mathrm{mg}$; Se, $0.16 \mathrm{mg}$; and I, $0.5 \mathrm{mg}$.

provided water without $B$. licheniformis. The chicks of groups 2 and 3 were provided water plus $1 \mathrm{ml}$ and $2 \mathrm{ml}$ of B. licheniformis suspension per liter of ration, respectively. The $1 \mathrm{ml} \mathrm{B}$. licheniformis treatment (B1) had $5.6 \times 10^{9}$ colony-forming units per $\mathrm{ml}$ drinking water, while the $2 \mathrm{ml}$ B. licheniformis treatment (B2) received probiotic prepared the same way at a dose rate of $1.1 \times 10^{10} \mathrm{cfu} / \mathrm{ml}$ of drinking water.

\section{Growth performance traits}

All birds in each group were weighed individually at hatch $(0 \mathrm{wk})$ and the end of each week. Body weight was assessed by dividing the total weight per experimental flock by the number of chicks alive. The amounts of added feed to each pen were recorded daily, and feed residues in each pen were weighed weekly. Feed consumption was therefore calculated on a weekly basis. In the controlled trial, body weight and feed intake were recorded for 6 growth stages, which are starter: the 1 st (hatch- $7 \mathrm{~d}), 2$ nd ( 8 to $14 \mathrm{~d}$ ) and 3rd (14 to $21 \mathrm{~d}$ ), and grower: 4th (21 to $28 \mathrm{~d}$ ), 5 th (28 to 35 d) and 6th (35 to 42 d). Daily weight gain and feed 
convention ratio (FCR) of each week, as well as starter period ( 0 to $3 \mathrm{wk}$ ), grower period ( 3 to $6 \mathrm{wk}$ ) and overall ( 0 to $6 \mathrm{wk})$ were calculated. In all trials mortality was recorded daily and weekly and reported as a cumulative percentage. All dead birds were removed daily in the morning.

\section{Chemical composition of chicken breast fillet}

At 42 days of age, 10 randomly chosen male chickens from each pen were slaughtered, and the breast muscles were dissected and stored at $-20^{\circ} \mathrm{C}$ prior to analysis. Protein and moisture content in chicken breast fillet was determined by the AOAC Official Method (AOAC, 1990). Fat content was determined with Soxhlet extraction (AOAC, 1990). Extraction residue was dried in an oven at $105^{\circ} \mathrm{C}$ for $24 \mathrm{~h}$ and cooled in a desiccator before being weighed to obtain dry solid content.

\section{Free amino acid analysis}

Both essential amino acids and flavor amino acids in samples were assayed as described below, in which the members of essential amino acids include Threonine, Lysine, Methionine, Valine, Isoleucine, Leucine, Phenylalanine, Tryptophan and Histidine, and the members of flavor amino acids include Serine, Glutamic acid, Glycine, Isoleucine, Leucine, Alanine and Proline. Samples were dissolved in water with methanol (1:1) during $30 \mathrm{~min}$ and centrifuged at $10,000 \mathrm{~g}$ for $5 \mathrm{~min}$, and supernatant was filtered through glass wool and stored at $-80^{\circ} \mathrm{C}$ until use. After centrifugation to separate soluble from insoluble material, $40 \mathrm{ml}$ of the supernatant were labeled with iTRAQ reagents (AA 45/32 kit, Applied Biosystems) as recommended by the manufacturer and analyzed on an Applied Biosystems 3200 Q TRAP LC/MS/MS system equipped with a RP-C18- column (150 mm length, $4.6 \mathrm{~mm}$ diameter, $5 \mathrm{~mm}$ particle size).

\section{Sensory evaluation}

Three groups of semi-trained students formed the sensory panel for the chicken breast fillet sensory evaluation. Each group consisted of 15 students with approximately equal number of males and females whose ages were between 20 to 28 years old. Chicken breast fillet samples were sliced into $1 \mathrm{~cm}$ thick pieces and grilled for about $45 \mathrm{~s}$ to reach an internal temperature of $71-75^{\circ} \mathrm{C}$, after which samples were provided to the sensory panel using a coded identifier. Before tasting, panelists were well instructed on the assessment criteria, meat attributes to be rated, and how to properly complete the questionnaire. Each treated sample was tasted by at least 3 different panelists. Drinking water was provided to cleanse off flavor from the last taste. Panelists used a 9-point hedonic scale to assess meat quality attributes. Sensory-textural attributes being scored were: meat colour (from extremely light to extremely dark), juiciness (from extremely dry to extremely juicy), aroma strength (from very weak to very strong), stickiness to the upper mouth cavity (from extremely gooey to extremely smooth)-which is very important, texture- the experience during chewing, and overall satisfaction (disagreeable to enjoyable).

\section{Statistical analysis}

Data were subjected to a one-way analysis of variance using the general linear models (GLM) procedure of SPSS 19.0.0 (2010). When significant treatment differences $(\mathrm{p}<0.05)$ were detected, means were separated using Duncan test.

\section{RESULTS}

\section{Growth performance}

To accurately assess the growth performance, we examined change patterns of broiler body weight gain (BWG) weekly during the whole production period (Figure 1). Table 2 clearly demonstrated the B. licheniformis tested in the study significantly improved the body weigh of the cocks. At 3 weeks of age, the $1 \mathrm{ml} \mathrm{B}$. licheniformis supplementation showed a significant increase in the body weight compared with the control group $(p<0.05)$, and this
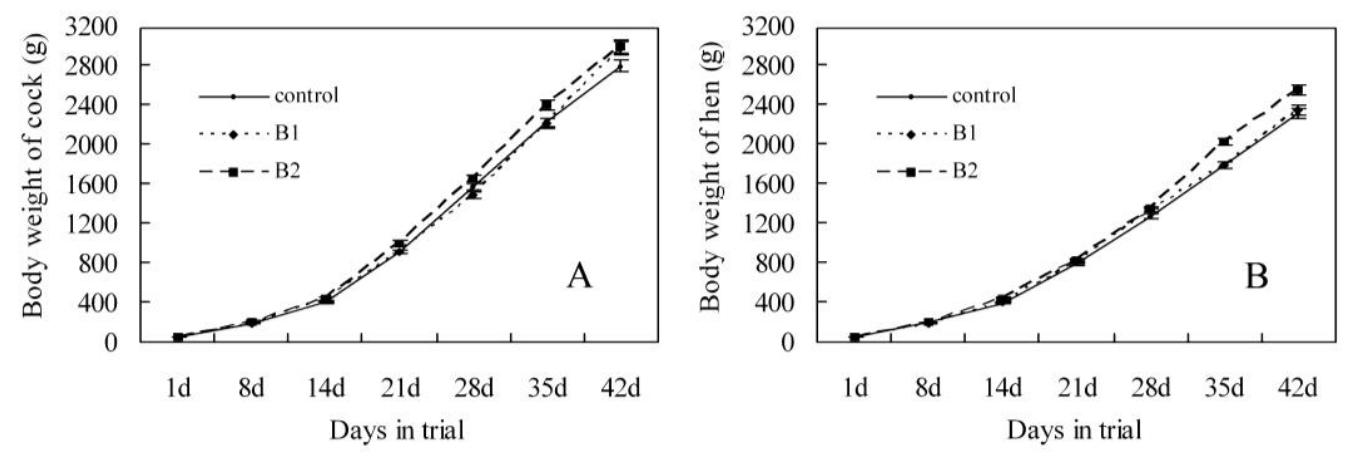

Figure 1. Evolution of broiler weekly body weight in the control group and Bacillus licheniformis supplemented groups. B1: $1 \mathrm{ml}$ Bacillus licheniformis supplemented treatment; B2: $2 \mathrm{ml}$ Bacillus licheniformis supplemented treatment. 
Table 2. Weekly body weight means of broiler fed on ration containing different concentration of probiotics

\begin{tabular}{|c|c|c|c|c|c|c|}
\hline \multirow{2}{*}{ Age in wk } & \multicolumn{3}{|c|}{ Daily weight gain of cocks treatment groups (g) } & \multicolumn{3}{|c|}{ Daily weight gain of hens treatment groups $(\mathrm{g})$} \\
\hline & Control & $\mathrm{B} 1^{1}$ & $\mathrm{~B} 2^{1}$ & Control & $\mathrm{B} 1^{1}$ & $\mathrm{~B} 2^{1}$ \\
\hline$\overline{0-1}$ & $20.26 \pm 0.250^{\mathrm{a}}$ & $20.69 \pm 0.251^{\mathrm{a}}$ & $23.38 \pm 0.249^{b}$ & $21.42 \pm 0.249^{\mathrm{a}}$ & $19.96 \pm 0.250^{\mathrm{b}}$ & $21.03 \pm 0.249^{\mathrm{a}}$ \\
\hline $1-2$ & $30.81 \pm 0.585^{\mathrm{a}}$ & $35.46 \pm 0.592^{b}$ & $32.90 \pm 0.587^{\mathrm{c}}$ & $28.49 \pm 0.490^{\mathrm{a}}$ & $31.50 \pm 0.485^{b}$ & $35.57 \pm 0.491^{\mathrm{c}}$ \\
\hline $2-3$ & $73.41 \pm 0.802^{\mathrm{a}}$ & $68.40 \pm 0.795^{\mathrm{b}}$ & $81.36 \pm 0.784^{\mathrm{c}}$ & $58.07 \pm 0.691^{\mathrm{a}}$ & $57.17 \pm 0.701^{\mathrm{a}}$ & $55.87 \pm 0.690^{\mathrm{a}}$ \\
\hline $3-4$ & $94.87 \pm 0.899^{\mathrm{a}}$ & $82.08 \pm 0.893^{\mathrm{b}}$ & $94.23 \pm 0.872^{\mathrm{a}}$ & $68.41 \pm 0.838^{\mathrm{a}}$ & $76.25 \pm 0.825^{b}$ & $74.37 \pm 0.840^{\mathrm{b}}$ \\
\hline $4-5$ & $93.76 \pm 1.540^{\mathrm{a}}$ & $105.62 \pm 1.554^{\mathrm{b}}$ & $106.90 \pm 1.519^{b}$ & $74.89 \pm 1.286^{\mathrm{a}}$ & $66.04 \pm 1.271^{\mathrm{b}}$ & $98.80 \pm 1.294^{\mathrm{c}}$ \\
\hline $5-6$ & $82.38 \pm 1.927^{\mathrm{a}}$ & $109.00 \pm 1.931^{\mathrm{b}}$ & $84.71 \pm 1.975^{\mathrm{a}}$ & $75.00 \pm 1.984^{\mathrm{a}}$ & $83.52 \pm 1.973^{b}$ & $74.30 \pm 1.953^{a}$ \\
\hline $0-3$ & $41.49 \pm 0.523^{\mathrm{a}}$ & $41.52 \pm 0.532^{\mathrm{a}}$ & $45.88 \pm 0.531^{b}$ & $36.00 \pm 0.459^{\mathrm{a}}$ & $36.21 \pm 0.459^{a}$ & $37.49 \pm 0.463^{\mathrm{a}}$ \\
\hline $3-6$ & $90.34 \pm 1.318^{\mathrm{a}}$ & $98.90 \pm 1.274^{\mathrm{b}}$ & $95.28 \pm 1.316^{\mathrm{b}}$ & $72.77 \pm 0.977^{\mathrm{a}}$ & $75.27 \pm 0.970^{\mathrm{a}}$ & $82.49 \pm 0.998^{b}$ \\
\hline $0-6$ & $65.91 \pm 0.889^{\mathrm{a}}$ & $70.21 \pm 0.903^{b}$ & $70.58 \pm 0.897^{b}$ & $54.38 \pm 0.708^{\mathrm{a}}$ & $55.74 \pm 0.714^{\mathrm{a}}$ & $59.99 \pm 0.717^{b}$ \\
\hline
\end{tabular}

${ }^{1} \mathrm{~B} 1=1 \mathrm{ml}$ Bacillus licheniformis supplemented treatment; B2 $=2 \mathrm{ml}$ Bacillus licheniformis supplemented treatment.

positive effect of probiotic on body weight persisted until 6 weeks of age $(\mathrm{p}<0.05)$. In addition, body weight of cocks treated by $2 \mathrm{ml}$ B. licheniformis supplement was significantly increased compared to the control group on 1 , 3 and $5 \mathrm{wk}(\mathrm{p}<0.05)$. It can be noticed that the two levels of probiotic groups showed significant increase in the body weight compared with the control group during the grower periods (3 to $6 \mathrm{wk})(\mathrm{p}<0.05)$. However, the initial average BWG of the cocks did not differ between the $1 \mathrm{ml} B$. licheniformis treatment group and the control group.

The weekly progress of hen's BWG was shown in (Figure 1B). The $1 \mathrm{ml} \mathrm{B}$. licheniformis treatment group showed a significant increase in the daily weight gain at 4 and 6 weeks of age $(\mathrm{p}<0.05)$, but had a decrease of BWG compared with controls on 5 wk $(\mathrm{p}<0.05)$ (Table 2). Moreover, no significant differences in growth performance were found between the $1 \mathrm{ml} \mathrm{B}$. licheniformis-treated birds and the control birds in the entire experimental period (Table 2). Whereas, the hens fed on the $2 \mathrm{ml} \mathrm{B}$. licheniformis had a greater average daily weight gain than control hens over weeks 0 to 4 and 0 to $6(\mathrm{p}<0.05)$.

\section{Feed conversion rate and mortality rate}

Feed intake for 0 to 3,3 to 6 and 0 to 6 wk was not influenced by $1 \mathrm{ml} \mathrm{B}$. licheniformis provision, whereas, the broiler supplemented by $2 \mathrm{ml} B$. licheniformis consumed significantly more feed than other two groups $(\mathrm{p}<0.05)$. Table 3 shows feed conversion ratios (FCR) which were

Table 3. Feed conversion ratios of chickens fed on rations containing different concentration of probiotics

\begin{tabular}{lccc}
\hline \multirow{2}{*}{ Age in wk } & \multicolumn{3}{c}{ Feed conversion ratio of treatment groups $(\mathrm{g})$} \\
\cline { 2 - 4 } & Control & $\mathrm{B} 1^{1}$ & $\mathrm{~B} 2^{1}$ \\
\hline $0-3$ & $1.61 \pm 0.022^{\mathrm{a}}$ & $1.60 \pm 0.022^{\mathrm{a}}$ & $1.58 \pm 0.022^{\mathrm{a}}$ \\
$3-6$ & $1.91 \pm 0.023^{\mathrm{a}}$ & $1.77 \pm 0.023^{\mathrm{b}}$ & $1.80 \pm 0.023^{\mathrm{b}}$ \\
$0-6$ & $1.81 \pm 0.021^{\mathrm{a}}$ & $1.72 \pm 0.021^{\mathrm{b}}$ & $1.73 \pm 0.021^{\mathrm{b}}$ \\
\hline
\end{tabular}

${ }^{1} \mathrm{~B} 1=1 \mathrm{ml}$ Bacillus licheniformis supplemented treatment; B2 $=2 \mathrm{ml}$ Bacillus licheniformis supplemented treatment. affected by supplement treatments. It can be seen that probiotic treatment groups showed lower FCR than the control group over 3 to 6 and 0 to $6 \mathrm{wk}(\mathrm{p}<0.05)$, however, there was no significant difference in means of FCR among three groups over 0 to $3 \mathrm{wk}$. In this study, improvement of feed conversion ratio was evident in B. licheniformis treated groups over control in growing period. Meanwhile, administration of both $1 \mathrm{ml}$ and $2 \mathrm{ml} \mathrm{B}$. licheniformis preparation had no effect on mortality during the whole process.

\section{Chemical composition}

The protein content, fat content and moisture content of chicken breast fillet are presented in Figure 2A-C. Meat of chickens fed on water without $B$. licheniformis had the lowest protein content $(84.92 \%)$ which was significantly different from that of the two probiotic-supplemented treatments $(\mathrm{p}<0.05)$. Meanwhile, the chicken breast fillet of the $2 \mathrm{ml} \mathrm{B}$. licheniformis supplemented treatment had a lower fat percentage $(5.47 \%)$ than the control $(7.99 \%)$ and the $1 \mathrm{ml} \mathrm{B}$. licheniformis supplemented treatment $(8.04 \%)$ $(\mathrm{p}<0.05)$. Unexpectedly, no significant changes were detected between the control and the $1 \mathrm{ml} \mathrm{B}$. licheniformis supplemented treatment. The moisture content of chicken breast fillet showed significant differences between the control $(74.99 \%)$ and the $1 \mathrm{ml}$ probiotic-supplemented treatment $(76.96 \%)$, but no differences were found between two treatments.

\section{Amino acids}

Figure 2D-F presents the determined amino acid content of chicken breast fillet among three groups. The total free amino acid content is higher in two probiotic-supplemented treatments in comparison to control $(\mathrm{p}<0.05)$, and $1 \mathrm{ml}$ B. licheniformis supplemented treatment had the highest amino acid content. Overall, there were more essential amino acids in two probiotic-supplemented treatments than in control. Especially, the essential and flavour amino acid 
A

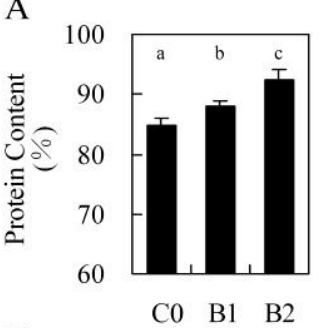

D

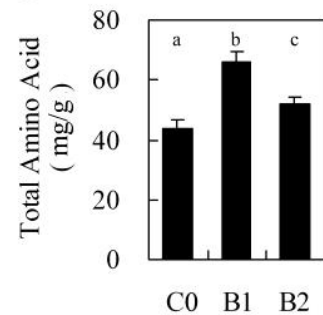

B
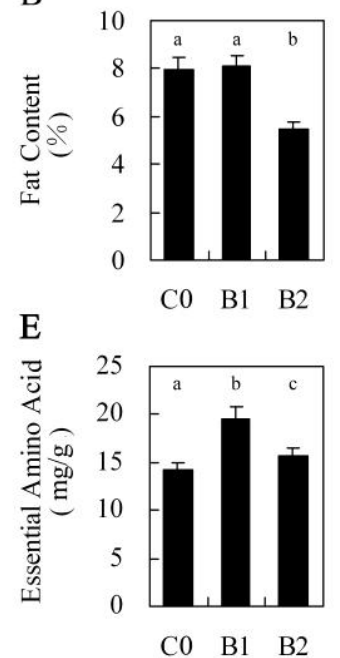

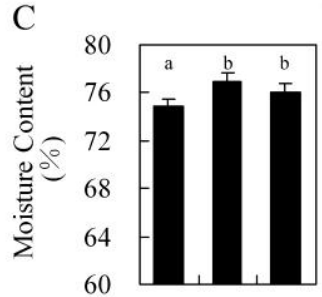

C0 $\quad$ B1 $\quad$ B2

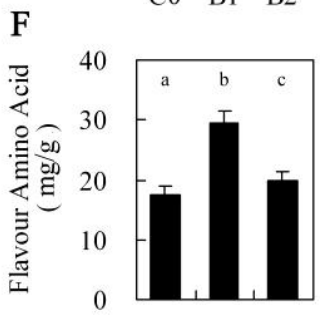

C0 $\quad$ B1 $\quad$ B2

Figure 2. Comparison of moisture content, protein content, fat content and amino acid content between the control group and Bacillus licheniformis treated groups. C0: control B1: $1 \mathrm{ml}$ Bacillus licheniformis supplemented treatment; $\mathrm{B} 2: 2 \mathrm{ml}$ Bacillus licheniformis supplemented treatment; \%: the percent of dry matter.

composition in chicken breast fillet from the $1 \mathrm{ml}$ B. licheniformis supplemented treatment was found to be higher than the other two groups ( $\mathrm{p}<0.05)$, and the control group had the lowest essential and flavour amino acid content.

\section{Sensory attributes}

To accurately assess the meat quality, we compared the meat colour, flavour, juiciness, aroma strength, and texture of chicken breast fillet between control and two probioticsupplemented treatments. Figure 3 shows lower values of meat colour and juiciness for control than two probioticsupplemented treatments $(p<0.05)$. It was also observed that two probiotic-supplemented treatments had significantly higher flavour pleasantness scores $(\mathrm{p}<0.05)$ than control. No significant difference was observed for the other two sensory attributes among treatments, suggesting that the aroma strength and texture of chicken breast fillet might not be related to the effect of $B$. licheniformis. However, the statistically significant effect of the probiotic on the improvement of overall satisfaction was found $(\mathrm{p}<0.05)$.

\section{DISCUSSION}

It could be seen from the study that the administration of B. licheniformis via the drinking water had beneficial effects on broiler performance. Based on results of the study on the evolution of broiler BWG, it was found that the

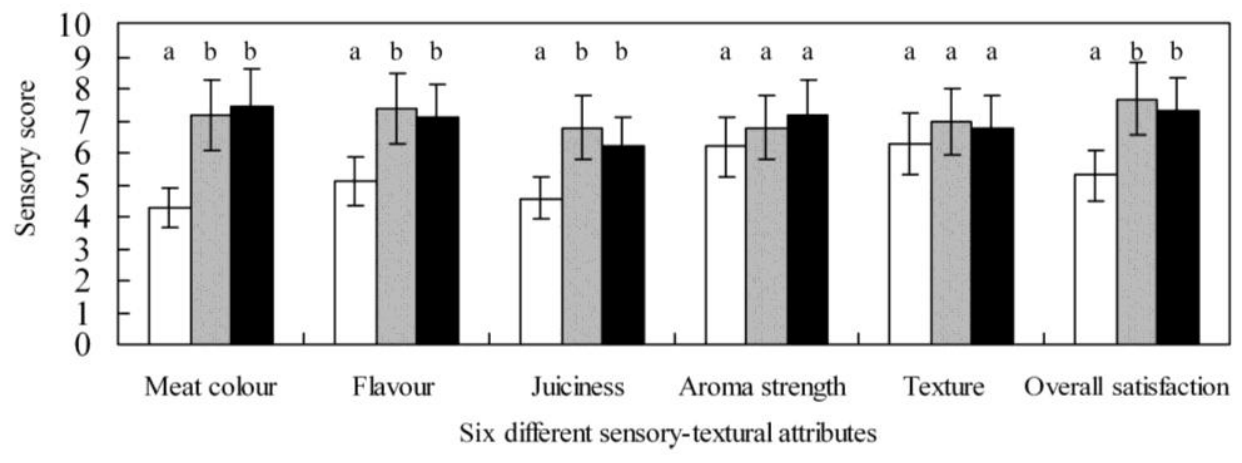

$\square$ Control $\square 1 \mathrm{ml}$ Bacillus licheniformis supplemented treatment $\quad 2 \mathrm{ml}$ Bacillus licheniformis supplemented treatment

Figure 3. Comparison of meat colour, flavour, juiciness, aroma strength, and texture of chicken breast fillet between the control group and Bacillus licheniformis treated groups. Each column represents the mean of 15 observations; meat colour, flavour, juiciness, aroma strength, and texture were assessed by the sensory panel using a hedonic (1 to 9) scale where the meat colour ranged from extremely light to extremely dark, flavour from extremely unpleasant to extremely enjoyable, juiciness from extremely dry to extremely juicy, aroma strength from very weak to very strong, and texture from extremely gooey to extremely smooth. Error bars represent standard deviations $(\mathrm{n}=15)$. 
B. licheniformis tested in the study significantly improved the BW of broilers. This finding is in agreement with several reports that demonstrated the probiotic supplemented to birds improved the weekly BW and daily BWG (Cavazzoni et al., 1998; Jin et al., 1998; Zulkifli et al., 2000; Timmerman et al., 2006; Liu et al., 2007; Mountzouris et al., 2007; Awad et al., 2009).

Furthermore, Table 2 clearly shows that the positive effect of probiotic on body weight did not manifest until 4 weeks of age, and the boost in the body weight became greater during the 4-6th wk, which agreed to the conclusion of Mohan et al. (1996) who observed the beneficial effect of probiotic on chicken occurred only after the 4th week of growth.

The enhancing effect of $B$. licheniformis supplement on FCR in the present trial agreed to several previous studies (Mountzouris et al., 2007; Awad et al., 2009; Karimi Torshizi et al., 2010). Appetite stimulation effects by probiotics have been reported in chickens, including increased lipid, protein, and mineral retention (Nahanshon et al., 1994). Feed conversion data showed that the increase in BWG was not a simple consequence of increased feed intake, since improvement in efficiency of feed utilization might also be involved. Data analysis also suggested that probiotic treatments caused a statistically significant improvement of feed conversion. Meanwhile, improvement of FCR was evident in probiotic groups during grower phases $(\mathrm{p}<0.05)$; what is more, the improvement in feed conversion ratio observed in this study is likely to be a result of the improved nutrient and energy utilization.

The microbial population change in intestine of broiler chickens has progressively been recognized as a significant factor impacting on health and growth performance (Fuller, 1989; Samanya and Yamauchi, 2002; Patterson and Burkholder, 2003). In the present study, supplementation of broilers with $B$. licheniformis increased the BWG and FCR during both grower and overall phases $(\mathrm{p}<0.05)$, suggesting an improved intestinal balance of microbial population in probiotic treatments. More importantly, the addition of probiotic may promote the growth of beneficial bacteria and thus provide a healthier intestinal system for better absorption of nutrients (Kelly et al., 1994; Rada and Rychly, 1995; Line et al., 1998; Salminen et al., 1998; Pascual et al., 1999).which was further confirmed by results summarized in Figure 2. Based on results from the determination of chemical composition in chicken breast fillet, it could be deduced that $B$. licheniformis might participate in the breakdown of food to produce materials more suitable for digestion, thus could affect the digestion efficiency of different substances in feed, and as a result to change the chemical composition of muscles. However, it remains unclear whether there was any added benefit in the cecal microflora composition. Therefore, further experiments are needed to verify this effect.

The term 'meat quality' has different definitions among producers, processors and consumers (Dikeman, 1994). It is possible to have uniformity for 'meat quality' definition for delimited areas of production that only consider the muscular development and the amount of fat cover at the carcass level (Nardonea and Valfre, 1999). The improvement of protein and amino acid content could be considered as positive factors, and the main negative effect of nutrition has been the excess of fat deposition (Larbier, 1991). Furthermore, increasing the ratio of essential amino acids and protein to energy may reduce the abdominal fat pad and improve feed conversion (Maybray and Waldroup, 1981; Smith and Pesti, 1998). In this study, we found that the chicken breast fillet of two B. licheniformis treatments appeared to have higher protein and amino acid content (Figure 2A, D-F). Treatment of $2 \mathrm{ml} \mathrm{B}$. licheniformis supplement had a lower fat percentage in both probiotic treatments (Figure 2B), which suggested that B. licheniformis intakes made the main contribution to chemical, nutritional and sensorial quality improvements. Consumers usually express their preference of meat according to organoleptic quality (taste, tenderness, colour, and juiciness) (Nardonea and Valfre, 1999). Results of sensory evaluation showed significant variations in the overall satisfaction ratio between two probiotic treated groups and the control group, and the degree of satisfaction in two probioticsupplemented treatments was higher than that in control. Therefore, it is fair to conclude that probiotic intake could result in improved growth performance and meat quality of broiler chickens. Moreover, the supplement via drinking water might also contribute to the improvement, which is consistent to previously studies that probiotic administration via drinking water appears to be superior to the more conventional in-feed supplementation method (Karimi Torshizi et al., 2010).

In conclusion, $B$. licheniformis supplement displayed a growth-promoting effect. It significantly increased BW and decreased feed gain ratios while no impact on the mortality was found. Furthermore, chicken breast fillet from B. licheniformis supplement treated broilers had increased the moisture, protein and amino acid content and decreased in fat content. Therefore, $B$. licheniformis can be a promising new growth promoter of the intestinal balance of microbial population in broiler. It has a remarkable potential in improving poultry production and meat quality.

\section{ACKNOWLEDGEMENTS}

The authors acknowledge the financial support for this study from the Fundamental Research Funds for the Central 
Universities (FRF-AS-09-003A, FRF-AS-10-001B).

\section{REFERENCES}

Alexopoulos, C., I. E. Georgoulakis, A. Tzivara, C. S. Kyriakis, A. Govaris and S. C. Kyriakis. 2004. Field evaluation of the effect of a probiotic-containing Bacillus licheniformis and Bacillus subtilis spores on the health status, performance, and carcass quality of grower and finisher pigs. J. Vet. Med. 51:306-312.

AOAC. 1990. Official methods of analysis (15th revised ed.). Washington, DC: Association of Official Analytical Chemists.

Awad, W. A., K. Ghareeb, S. Abdel-Raheem and J. Böhm. 2009. Effects of dietary inclusion of probiotic and synbiotic on growth performance, organ weights, and intestinal histomorphology of broiler chickens. Poult. Sci. 88:49-56

Cavazzoni, V., A. Adami and C. Cstrivilli. 1998. Performance of broiler chickens supplemented with Bacillus coagulans as probiotic. Br. Poult. Sci. 39:526-529.

Dikeman, M. E. 1994. Genetics of meat quality. In: Proc. 5th World Congress on Genetics applied to livestock production, 437-449.

Fuller, R. 1989. Probiotics in man and animals. J. Appl. Bacteriol. 66:365-378.

Jin, L. Z., Y. W. Ho, N. Abdullah and S. Jalaludin. 1998. Growth performance, intestinal microbial populations, and serum cholesterol of broilers fed diets containing Lactobacillus cultures. Poult. Sci. 77:1259-1265.

Kabir, S. M. L., M. M. Rahman, M. B. Rahman, M. M. Rahman and S. U. Ahmed. 2004. The dynamics of probiotics on growth performance and immune response in broilers. Int. J. Poult. Sci. 3:361-364.

Kalavathy, R., N. Abdullah, S. Jalaludin and Y. W. Ho. 2003. Effects of Lactobacillus cultures on growth performance, abdominal fat deposition, serum lipids and weight of organs of broiler chickens. Br. Poult. Sci. 44:139-144.

Karimi Torshizi, M. A., A. R. Moghaddam, S. Rahimi and N. Mojgani. 2010. Assessing the effect of administering probiotics in water or as a feed supplement on broiler performance and immune response. Br. Poult. Sci. 51:178-184.

Kelly, D., R. Begbie and T. P. King. 1994. Nutritional influences on interactions between bacteria and the small intestinal mucosa. Nutr. Res. Rev. 7:233-257.

Knap, I., B. Lund, A. B. Kehlet, C. Hofacre and G. Mathis. 2010. Bacillus licheniformis prevents necrotic enteritis in broiler chickens. Avian Dis. Jun. 54: 931-935.

Kyriakis, S. C., V. K. Tsiloyiannis, J. Vlemmas, K. Sarris, A. C. Tsinas, C. Alexopoulos and L. Jansegers. 1999. The effect of probiotic LSP 122 on the control of post-weaning diarrhoea syndrome of piglets. Res. Vet. Sci. 67:223-228.

Larbier, M. and G. Uzu. 1991. Control of carcass fatness and quality in broilers: nutritional aspects. Proceedings: 8th European Symposium on Poultry Nutrition, Venezia-Mestre, Italy, 14-17, October 1991. pp. 198-209.

Line, J. E., J. S. Bailey, N. A. Cox, N. J. Stern and T. Tompkins. 1998. Effect of yeast-supplemented feed on Salmonella and Campylobacter populations in broilers. Poult. Sci. 77:405-410.

Liu, J. R., S. F. Lai and B. Yu. 2007. Evaluation of an intestinal Lactobacillus reuteri strain expressing rumen fungal xylanase as a probiotic for broiler chickens fed on a wheat-based diet. Br. Poult. Sci. 48:507-514.

Maybray, C. J. and P. J. Waldroup. 1981. The influence of dietary energy and amino acid levels on abdominal fat pad development of the broiler chicken1. Poult. Sci. 60:151-159.

Mohan, B., R. Kadirvel, A. Natarajan and M. Bhaskaran. 1996. Effect of probiotic supplementation on growth, nitrogen utilization and serum cholesterol in broilers. Br. Poult. Sci. 37:395-401.

Mountzouris, K. C., P. Tsirtsikos, E. Kalamara, S. Nitsch, G. Schatzmayr and K. Fegeros. 2007. Evaluation of the efficacy of a probiotic containing lactobacillus, bifidobacterium, enterococcus, and pediococcus strains in promoting broiler performance and modulating cecal microflora composition and metabolic activities. Poult. Sci. 86:309-317.

Nahashon, S. N., H. S. Nakaue, S. P. Snyder and L. W. Mirosh. 1994. Performance of single comb white leghorn layers fed corn-soybean meal and barley-corn-soybean meal diets supplemented with a direct-fed microbial. Poult. Sci. 73:17121723.

Nardonea, A. and F. Valfrè. 1999. Effects of changing production methods on quality of meat, milk and eggs. Livest. Prod. Sci. 59:165-182.

Osipova, I. G., I. B. Sorokulova, E. A. Vasil'eva and E. V. Budanova. 2005. Pre-clinical trials of new spore probiotics. Vestn. Ross. Akad. Med. Nauk 36-40.

Owings, W. J., D. L. Reynolds, R. J. Hasiak and P. R. Ferket. 1990 Influence of dietary supplementation with Streptococcus faecium M-74 on broiler body weight, feed conversion, carcass characteristics, and intestinal microbial colonization. Poult. Sci. 69:1257-1264

Pascual, M., M. Hugas, J. I. Badiola, J. M. Monfort and M. Garriga. 1999. Lactobacillus salivarius CTC2197 prevents Salmonella enteritidis colonization in chickens. Appl. Environ. Microbiol. 65:4981-4986.

Patterson, J. A. and K. M. Burkholder. 2003. Application of prebiotics and probiotics in poultry production. Poult. Sci. 82:627-631.

Rada, V. and I. Rychlý. 1995. The effect of Lactobacillus salivarius administration on coliform bacteria and enterococci in the crop and cecum of broiler chickens. Vet. Med. (Praha) 40:311-315.

Salminen, S., C. Bouley, M. C. Boutron-Ruault, J. H. Cummings, A. Franck, G. R. Gibson, E. Isolauri, M. C. Moreau, M. Roberfroid and I. Rowland. 1998. Functional food science and gastrointestinal physiology and function. Br. J. Nutr. 80 (Suppl. 1):S147-171.

Samanya, M. and K. E. Yamauchi. 2002. Histological alterations of intestinal villi in chickens fed dried Bacillus subtilis var. natto. Comp. Biochem. Physiol. A Mol. Integr. Physiol. 133:95-104.

SCAN. 2000b. Report of the scientific committee on animal nutrition on product BioPlus $2 \mathrm{~B}$ for use as feed additive. European commission, health and consumer protection directorate-general. (SCAN) Scientific Committee on Animal Nutrition

Sögaard, D. H. and T. Suhr-Jessen. 1990. Microbials for feed beyond lactic acid bacteria. Feed International. 11:32-38. 
Cutting, S. M. 2011. Bacillus probiotics. Food Microbiol. 28:214220.

Smith, E. R. and G. M. Pesti. 1998. Influence of broiler strain cross and dietary protein on the performance of broilers. Poult. Sci. 77:276-281.

Spackman, D. H., W. H. Stein and S. Moore. 1958. Automatic recording apparatus for use in the chromatography of amino acids. Anal. Chem. 30:1190-1206.

SPSS, 2010. SPSS Version 19.0.0 for Windows. SPSS Inc., USA.

Steel, R. G. D. and J. H. Torrie. 1980. Principles and procedures of statistics. A Biometrical Approach. McGraw-Hill, New York, NY.

Tannock, G. W. 1999. What we know and need to know. Biotechnol. Adv. 17:691-693.
Timmerman, H. M., A. Veldman, E. van den Elsen, F. M. Rombouts and A. C. Beynen. 2006. Mortality and growth performance of broilers given drinking water supplemented with chicken-specific probiotics. Poult. Sci. 85:1383-1388.

Tomasik, P. J. and P. Tomasik. 2003. Probiotics and prebiotics. Cereal Chem. 80:113-117.

Tortuero, F. 1973. Influence of the implantation of Lactobacillus acidophilus in chicks on the growth, feed conversion, malabsorption of fats syndrome and intestinal flora. Poult. Sci. 52:197-203.

Zulkifli, I., N. Abdullah, N. M. Azrin and Y. W. Ho. 2000. Growth performance and immune response of two commercial broiler strains fed diets containing Lactobacillus cultures and oxytetracycline under heat stress conditions. Br. Poult. Sci. 41:593-597. 